\title{
Lipid Deposition at the Limbus
}

\author{
S. M. CRISPIN \\ Bristol
}

\begin{abstract}
Summary
Lipid deposition at the limbus is a feature of familial and non-familial dyslipoproteinemias and can also occur without apparent accompanying systemic abnormality. Hyperlipoproteinemia, most notably type II hyperlipoproteinemia, is frequently associated with bilateral corneal arcus, with less common association in types III, IV and V. Diffuse bilateral opacification of the cornea with accentuation towards the limbus is a feature of HDL deficiency syndromes and LCAT deficiency. Whereas the lipid accumulation of hyperlipoproteinemia may be representative of excessive insudation of lipoprotein from plasma into the cornea that of hypoliproteinemia is more likely to be a consequence of defective lipid clearance. The situation is yet further complicated by the modifying influences of secondary factors, both local and systemic.
\end{abstract}

Lipid may be deposited at the limbus in a variety of situations; most commonly it accumulates as a consequence of excessive lipid entry or defective lipid clearance over a long period of time, but this is not invariably

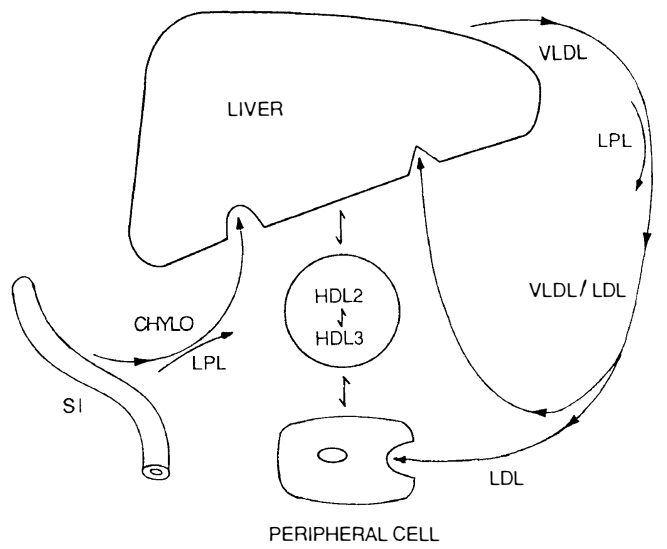

Fig. 1. Outline of central pathways of lipoprotein metabolism. so. Both local and systemic factors can influence lipid deposition in this region and their inter-relationships are complex and often poorly understood. Some of the local factors which have been investigated include normal and abnormal structure and function; the effects of temperature and vasculature; and the modifying influences of certain ocular disorders.

Local lipoprotein metabolism of cornea and limbus has received little study but there is a wealth of information available concerning systemic plasma lipoproteins in health and disease and a number of dyslipoproteinemias have been reported in which corneal lipid deposition is one of the clinical features. In view of this association, it is important to examine briefly some aspects of lipoprotein metabolism; further information can be obtained from recent reviews. ${ }^{1.2}$

\section{Lipoprotein Metabolism}

Normal human lipoprotein metabolism is

Correspondence to: Dr. S. M. Crispin, School of Veterinary Science, University of Bristol, Langford House, Langford, Bristol BS18 7DU. 
summarised very simply in Figure 1. Lipoproteins consist of a hydrophobic core of cholesteral esters and triglycerides surrounded by a membrane-like shell of free cholesterol, phospholipid and apolipoproteins. The apolipoproteins increase in relative proportion as the size of the lipoprotein diminishes and concomitant with this there is progressive decrease in lipid content.

Triglyceride rich lipoproteins are secreted from the small intestine as large $(>75 \mathrm{~nm})$ chylomicrons which contain apoliprotein B-48 (apo B-48). The triglyceride of chylomicrons undergoes lipolysis through the action of apo C-11 activated lipoprotein lipase (LPL) in peripheral capillaries and the resulting chylomicron remnants are rapidly cleared by receptor mediated hepatic uptake.

The liver also secretes triglyceride-rich particles called very low density lipoproteins (VLDL) of some $30-90 \mathrm{~nm}$ diameter which contain apo B-100, as well as apo C and E, and these too are degraded by LPL. Some VLDL remnants are removed by the liver and others are converted to low density lipoprotein (LDL) via intermediate density lipoprotein (IDL).

Low density lipoprotein is the major cholesterol transporter in man, it is of some $20-25 \mathrm{~nm}$ diameter and rich in apo-B. LDL is removed from the circulation by specific cell surface receptors which recognise both apo B-100 and apo E (B/E receptors). B/E receptors are found on peripheral cells like fibroblasts, smooth muscle cells and endothelial cells as well as in the liver. By a well defined pathway ${ }^{3} \mathrm{LDL}$ is taken into the cell and free cholesterol and amino acids are liberated by lysosomal hydrolysis. The free cholesterol supresses the activity of 3-hydroxy 3 methylglutaryl coenzyme A reductase (HMG Co A reductase) which controls the rate determining step in cholesterol biosynthesis, it also down regulates production of LDL receptors and stimulates its own re-esterification by activating acyl-COA: cholesterol acyltransferase (ACAT). The overall effect of re-esterification is to shift the balance of fatty acids in the cholesterol esters from a polyunsaturated to a more saturated form, most readily appreciated by examination of $\mathrm{C} 18: 2$ (cholesterol linoleate) to C18: 1 (cholesterol oleate) ratios.

High density lipoproteins (HDL) form a very heterogeneous group. They are derived from the catabolism of both VLDL and chylomicrons as well as by direct synthesis from the liver and small intestine. The newly synthesised (nascent) HDL is disc shaped and contains no esterified cholesterol. Production of mature spherical particles of $\mathrm{HDL}_{3}$ (diameter $7 \mathrm{~nm}$ ) and $\mathrm{HDL}_{2}$ (diameter $10 \mathrm{~nm}$ ) is dependent on the plasma cholesterol esterifying enzyme lecithin cholesterol acyl transferase (LCAT) or, more specifically, alphaLCAT as beta-LCAT is associated with esterification of LDL and VLDL cholesterol. Phospholipid is the more abundant lipid component of most HDL, followed by cholesterol ester. Apo A-1 (a co-factor for LCAT) and apo A-11 (a structural protein) are the major HDL apolipoproteins, with $\mathrm{B}, \mathrm{C}$ and $\mathrm{E}$ as minor components.

HDL appears to be involved in reverse cholesterol transport from the peripheral tissues to the liver; by removing cholesterol from these sites it can be said to have anti-atherogenic activity. It is therefore particularly significant that HDL rather than LDL is the major transporter of plasma cholesterol in the dog, a species known to be highly resistant to naturally occurring atherosclerosis. Whether or not these innate differences of cholesterol transport make any difference to the pathogenesis of corneal stromal lipid deposition is a matter of conjecture.

\section{Local Factors and Lipid Deposition at the Limbus}

Lipids and lipoproteins probably reach the corneal stroma from the limbal vessels. Distribution within the stroma depends upon local blood vessels, local temperature effects, the size and properties of the lipids and lipoproteins, the potential for interaction with other plasma constituents and corneo-limbal components, and the organisation of the corneal stroma.

\section{Blood vessels}

Lipid can migrate right across the vessel wall in capillaries ${ }^{4}$ and normal endothelium is permeable to plasma macromolecules. ${ }^{5}$ Lipid 
transport is more rapid in newly formed vessels and in inflamed or damaged vessels, ${ }^{6,7,8}$ increased temperature may also increase local capillary permeability. ${ }^{9}$

No enzyme degradative system for cholesterol exists in the blood vessel wall whereas phospholipids and triglycerides can be influenced by phospholipases and triglyceride lipases respectively. ${ }^{10}$ There have been no studies of enzyme degradation in the limbal blood vessels but it is possible that lipids and lipoproteins delivered to the stroma are modified on arrival. Corneal lipid deposition can be dramatic when peri-limbal blood vessels are inflamed or if corneal neovascularisation has occurred, whether as ghost vessels in quiet eyes or as part of active inflammation. ${ }^{11,12,13}$

Lipid keratopathy, a vascularised form of lipid deposition, is perhaps a consequence of unmodified lipid deposition. For inflamed or new vessels, especially in the presence of corneal damage, will allow access by lipoproteins of all sizes. The most marked depositions occur if the human or animal is also hyperlipoproteinemic, usually hypercholesterolemic, when neovascularisation occurs. ${ }^{13.14}$ The lipid keratopathy varies in extent, position and depth according to cause (Figs. 2-5).

Lipid keratopathy is typified by extensive

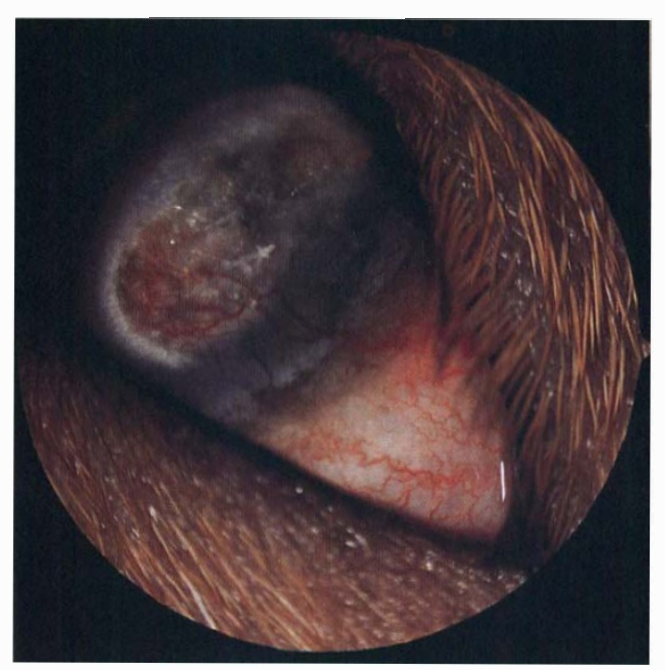

Fig. 2. Jack Russell Terrier (female). Lipid keratopathy le ft eye following cat scratch 9 months earlier. Mild increase in HDL cholesterol. cell necrosis in progressive lesions, affecting particularly lipid-filled fibroblasts (keratocytes) rich in esterified cholesterol; cell death results in the deposition of extracellular crystalline and non-crystalline material, mainly free and esterified cholesterol and varying quantities of phospholipid. ${ }^{11,13}$

In humans lipid keratopathy is much commoner in women than men, a review of the existing literature revealed a ratio of approximately $70: 30$ per cent. ${ }^{13}$ Few studies have examined the lipoprotein profile in detail in humans which is odd in view of the reported similarity to atherosclerotic plaques. ${ }^{11.15}$ In studies of dogs with naturally occurring lipid keratopathy raised cholesterol-enriched plasma HDL was the commonest finding ${ }^{13}$ and lipid keratopathy is the usual sequel to ingestion of high fat diets rich in cholesterol in the rabbit. The predominantly peripheral distribution of lipid in hypercholesterolemic rabbits bears a superficial resemblance to human arcus; however there is no lucid interval of Vogt, the lesion is vascularised and there are abundant quantities of acicular birefringent crystals in addition to numerous fat-filled cells. ${ }^{14}$

It is possible to produce regression of some lipid keratopathies in dogs, humans and rabbits. ${ }^{13,16,17}$ In dogs this situation is achieved by restoration of normolipoproteinemia and local effects within the cornea. Effective corneal vascularisation permits lipid clearance by haematogenous macrophages and multinucleate giant cells, other compensatory devices such as increased phospholipid synthesis and liposome formation play a lesser role. Whilst blood vessels may be crucial in delivering lipid to the cornea they may also be instrumental in making possible its clearance.

\section{Temperature}

Blood flow and corneal temperature are interrelated in that a rise in temperature is associated with a corresponding increase in the capillary filtration coefficient. ${ }^{18}$ Regional temperature differences may be relevant to long term corneal lipid deposition such as human arcus in which it has been demonstrated that arcus commences in the warmer regions of the cornea and that if a unilateral arcus is present it is the warmer eye which is 


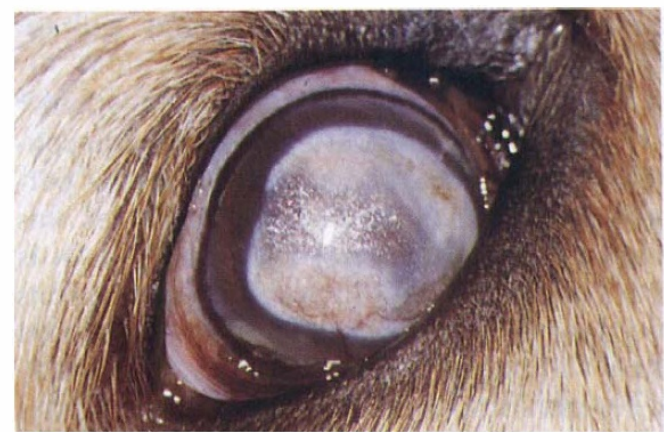

Fig. 3. Golden Retriever (castrated male). Lipid keratopathy right eye-following diffuse episcleritis. Mild hypercholesterolemia and hypertriglyceridemia.

affected. ${ }^{19,20}$ Arcus can also be deflected by conditions which modify local blood flow ${ }^{11,13,20,21}$ (Fig. 6) and it is possible to have both arcus and lipid keratopathy in the same cornea.

Arcus senilis is a normal feature of human ageing (Fig. 7) but its incidence shows marked individual and racial variation ${ }^{22}$ and there is an inconsistent relationship between arcus and hyperlipoproteinemia ${ }^{23}$ which will be considered when systemic factors are discussed. In dogs there are interesting breed variations in susceptibility to corneal lipid deposition.

Whilst warmth can encourage lipid and lipoprotein deposition the converse is also true and remobilisation of deposited lipid may be more difficult in cooler areas. In Tangier disease, for example, cholesterol ester-rich lipid accumulates in several sites and is par-

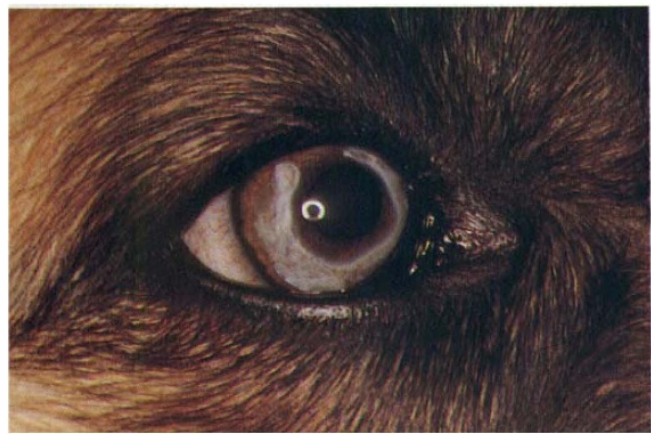

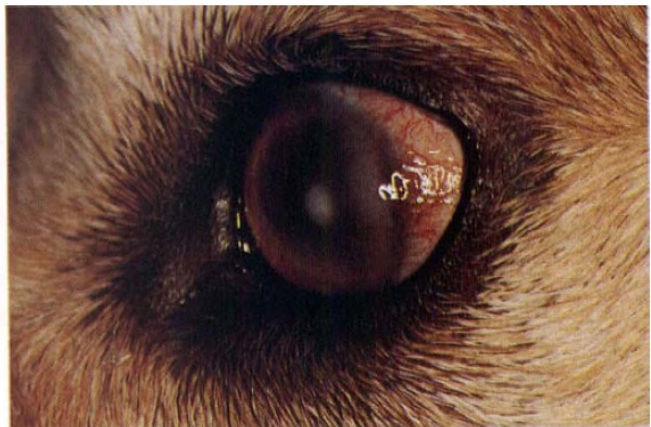

Fig. 4. Labrador (castrated male). Diffuse and circumscribed lipid deposition left eye-following scleritis. Mild hypercholesterolemia and hypertriglyceridemia.

ticularly obvious in areas below body core temperature like the tonsils and medial and lateral quadrants of the cornea. ${ }^{24}$ It is possible that the cooler regions provide a critical temperature difference which slows melting of the cholesterol ester liquid crystals and impedes their utilisation.

\section{Physical and Chemical Modifications to Lipoprotein and Lipids}

This is a complex subject which has been little studied in the cornea. There are, however, some excellent reviews concerned with atherosclerosis which are relevant to corneal lipid deposition in relation to both the lipids and lipoproteins, ${ }^{25,26,27}$ and the corneal fibroblasts and intercellular matrix. ${ }^{3,28}$

The normal human cornea has a very orderly arrangement of collagen fibrils

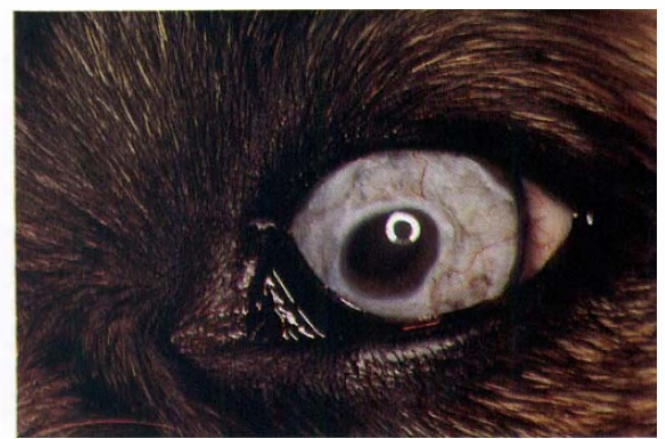

Fig. 5. Afghan Hound (female). Right and left eye; lipid deposition occurred in apparently normal cornea, affecting the left eye before the right. Intermittent mild hypercholesterolemia and marked hypertriglyceridemia; repeated blood samples indicated normolipoproteinemia on most occasions. 


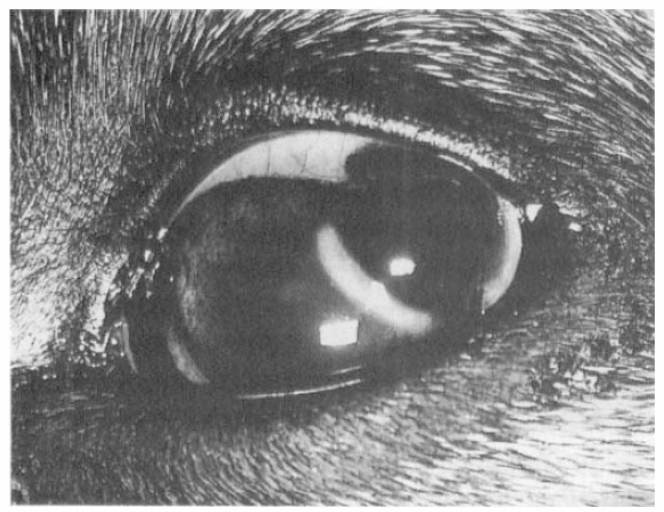

Fig. 6. German Shepherd Dog (neutered female). Corneal arcus left eye at the edge of a limbal melanoma. Normolipoproteinemia.

centrally, whereas at the limbus there are fewer fibrils of more diverse diameter spaced further apart. The organisation of collagen fibrils is directly related to the acidic glycosaminoglycan content which is highest centrally. The small, negatively charged, keratan sulphate molecules on the surface of the proteoglycan subunits, which coat the collagen fibrils, create a negatively charged field around each collagen fibril which maintains precise spacing of the fibrils by mutual repulsion. The greater spacing found at the periphery is probably due to the larger size of the negatively charged chondroitin sulphate molecules which are absent from central cornea. ${ }^{29}$

Maurice $^{30}$ suggested that the largest molecule capable of diffusing across unswollen human cornea would be of approximately $12 \mathrm{~nm}$ diameter. The size of intact lipoproteins is such that only free fatty acid-albumin complexes and HDL will be theoretically capable of such diffusion. Other lipoproteins (LDL, VLDL and chylomicrons) are too large to make free diffusion of intact lipoprotein a practical possibility in normal cornea.

In addition to the potential for free diffusion there are, however, other mechanisms to be considered; for example the liproproteins may dissociate, the glycosaminoglycans (GAG) might act as a molecular sieve and there is the possibility of specific ionic complex formation. There is some evidence from work on atherosclerosis that lipids can be bound by collagen, GAGS and proteoglycans. ${ }^{28}$

In relation to arcus, Fielder and others ${ }^{20}$ showed that intact LDL is an inconsistent constituent of arcus and no evidence for persistence of GAG-lipoprotein complexes was found in arcus material examined, ${ }^{30}$ so it is possible that GAG-lipoprotein interactions do not occur in the cornea or are concerned only with initial localisation. This is a slightly different situation from that of atherosclerosis where apo B-100 segments with positively charged side chains have been shown to mediate the action of LDL with chondroitin sulphate. ${ }^{31}$

Other important interactions which may occur are between the lipoproteins themselves, between the lipids of cell membranes and between the lipoproteins and corneal fibroblasts. Whether these interactions occur between intact lipoproteins with minor compositional changes, or whether between dissociated lipoprotein constituents, is poorly understood. However it is clear that lipoproteins and lipids deposited at the limbus do undergo both chemical and physical modifications. Evidence for chemical modification comes from studies of corneal arcus and lipid keratopathy. Two fatty acid profile studies on corneae with arcus, analysing total lipids ${ }^{32}$ or the cholesterol ester fraction, ${ }^{30}$ both indicate a lower linoleate and higher saturated fatty acid content than would be expected from unmodified LDL which is rich in linoleic acid

In lipid keratopathy fibroblast involvement is an early feature of naturally occurring cases

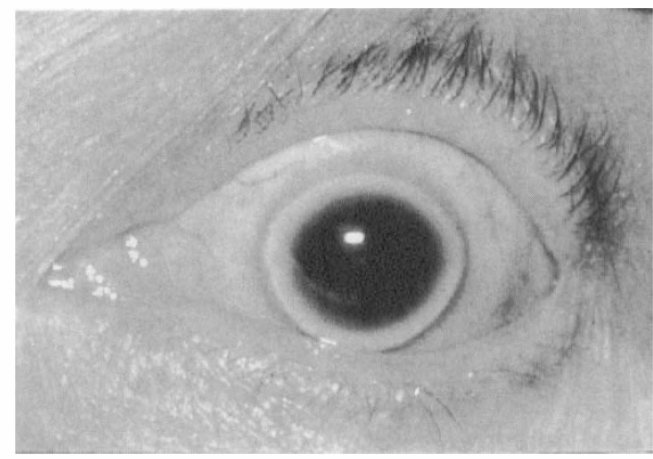

Fig. 7. Human (male)-Corneal arcus (bilateral). Normolipoproteinemia. (With acknowledgement to Professor A. F. Winder.) 
in dogs and humans and experimental lesions in rabbits. ${ }^{13}$ Once lipoproteins have been chemically modified within the cornea physical alterations may follow. Mobility is related to the physical state of the lipid (liquid droplet, liquid crystal, solid crystal) and properties such as solubility, chain length and saturation are relevant. It is of interest that the lipids which accumulate in atherosclerosis and lipid keratopathy (cholesterol, cholesterol esters and phospholipids) are water insoluble and in this context it is worth remembering that the presence of predominantly crystalline, high melting point lipids, does not necessarily indicate their exclusive production, but rather the more rapid removal of non-crystalline, lower melting point, lipids. Central cornea is some 3.6 degrees $\mathrm{C}$ below body temperature in humans whilst the limbus is approximately 1 degree $\mathrm{C}$ warmer than the centre. Cholesterol esters can undergo reversible thermal transitions at around body temperature associated with a liquid crystalline order-disorder phase change. In intact LDL, for example, the amount of triglyceride present can influence the fluidity of the cholesterol esters. ${ }^{33}$ Increasing the amount of triglyceride lowers the temperature at which the liquid to smectic liquid crystalline transition occurs. There is, however, individual variation, so that although the peak transition temperature is approximatley 30 degrees $\mathrm{C}$ some individuals will have a fraction of LDL cholesterol esters in a smectic-like state at body temperature. In addition, patients with homozygous familial hypercholesterolemia (FH) have less triglyceride in LDL compared to normals. These findings are therefore of significance with regard to peripheral lipid deposition in both normolipoproteinemic and hyperlipoproteinemic individuals.

\section{Systemic Factors and Lipid Deposition at the Limbus}

\section{Hyperlipoproteinemia}

Raised lipoprotein levels are found in both primary inherited types of hyperlipoproteinemia and secondary non-inherited types.

\section{Hyperalphalipoproteinemia}

Corneal opacification has been reported in association with some cases of hyper- alphalipoproteinemia although the corneal appearance was not described. ${ }^{34}$ In patients with corneal opacification apo A-1, A-11, C111 and E were elevated and there was defective net transfer of cholesterol ester from HDL and decreased hepatic lipase activity. HDL particles were markedly enlarged and LDL particles were small and polydispersed.

\section{Hyperlipoproteinemia and Corneal Arcus}

The World Health Organisation study group ${ }^{35}$ classified hyperlipoproteinemia into six types; the divisions are somewhat arbitrary as they are based on the patterns of lipoprotein elevation rather than knowledge of the specific defect involved. There are common clinical features between some of the types and extensive modification can also occur because of treatment.

Peripheral lipid deposition is a feature of types II, III, IV and V, notably as xanthomata and corneal arcus. Corneal arcus is common in type II, less so in type IV and develops occasionally in types III and IV, it is probably a visible manifestation of excessive insudation of plasma lipoprotein.

\section{Type IIa Hyperlipoproteinemia}

Inherited type IIa hyperlipoproteinemia $(\mathrm{FH})$ is due to a qualitative or quantitative defect in LDL receptors. Hence LDL and apo-B levels are increased as mechanisms for cellular uptake of LDL and consequent supression of intracellular cholesterol synthesis are defective. In $\mathrm{FH}$ homozygotes the resulting hypercholesterolemia is such that survival beyond twenty years is rare and death usually occurs because of premature atherosclerotic heart disease. Heterozygotes develop variable degrees of the same clinical manifestations as homozygotes at a slower rate. ${ }^{36.37}$ Premature arcus is common (Fig. 8) usually before 10 years of age in homozygotes. ${ }^{36}$

In secondary type 11a hypercholesterolemia it is also possible that receptor mediated catabolism of LDL is abnormal, possibly influenced by factors such as diet and hormones. The defect can be reversed by appropriate therapy, for example thyroxine administration for hypothyroidism. ${ }^{38}$

The inconsistent relationship between arcus and hyperlipoproteinemia was clarified 


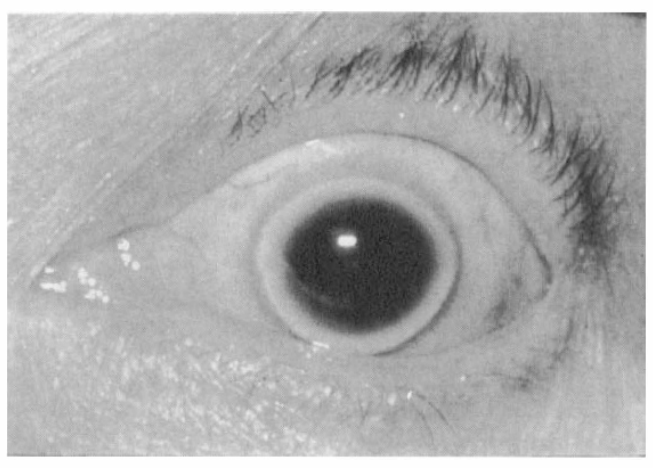

Fig. 8. Human (female)-Corneal arcus (bilateral). Patient heterozygous for FH. (With acknowledgement to Professor A. F. Winder.)

by Winder ${ }^{23}$ in a study of patients with homozygous and heterozygous $\mathrm{FH}$ in which it was shown that arcus development correlated with age and thus to the duration of hyperlipoproteinemia, rather than extent or pattern of hyperlipoproteinemia.

Arcus lipoides corneae is a very rare finding in dogs and is always associated with hyperlipoproteinemia. ${ }^{39}$ In affected animals it is usually secondary to primary acquired hypothyroidism with raised plasma HDL (as cholesterol enriched $\mathrm{HDL}_{\mathrm{c}}$ alpha 2 lipoprotein) LDL (beta) and VLDL (pre-beta) as the commonest laboratory findings. Initially it resembles human arcus..$^{40}$ In both there is fine, extracellular, granular sudanophilia of the stroma, and in Descemet's membrane a marked sudanophilia with characteristic hyaline quality. In man there is a similar hyaline type of sudanophilia in Bowman's membrane; in the dog, which lacks Bowman's layer, this lipid deposits immediatley beneath the basal lamina of the corneal epithelium in the subepithelial zone. As the canine arcus becomes denser it becomes vascularised, the lucid interval of Vogt is usually absent and scintillating crystals can be observed with the slit lamp biomicroscope. Microscopy of affected corneas demonstrates intracellular involvement with cell death and necrosis contributing to the crystalline appearance.

Appropriate treatment with thyroxine reduces the density and extent of the corneal arcus in a proportion of cases. It is of interest that the arcus forms preferentially in the warmest regions of the cornea; beneath the upper and lower lids as in man, but also in the region of the third eyelid (Figs. 9-12). The lack of senile arcus formation in dogs may be indicative of more effective scavenger mechanisms at the limbus, perhaps connected with the high levels of HDL which are concerned with cholesterol transport in this species.

\section{Type IIb Hyperliproproteinemia}

In type IIb hyperlipoproteinemia the underlying defect may be related to increased synthesis of apo B which results in overproduction of VLDL particles coupled with decreased catabolism of LDL. The clinical course is rather less severe than for type IIa but clinical findings are similar.

\section{Type III Hyperlipoproteinemia}

Corneal arcus is an occasional finding in type III hyperlipoproteinemia (broad beta disease) which is characterised by the presence of abnormal, and large, cholesterol-rich betaVLDL. The accumulation of beta VLDL in plasma is due to defective apo $\mathrm{E}$ mediated removal of chylomicron remnants.

\section{Type IV Hyperlipoproteinemia}

Type IV hyperlipoproteinemia is characterised by raised VLDL. The arcus which forms is more diffuse than that seen with hypercholesterolemia and excess of LDL, perhaps reflecting some differences in the mechanisms of lipid accumulation within the cornea. ${ }^{41}$

\section{Type $V$ Hyperlipoproteinemia}

Type V hyperlipoproteinemia is associated with chylomicronemia and hypertriglyceridemia. It bears some resemblance to type I hypertriglyceridemia in which chylomicronemia is the predominant finding. Type $\mathrm{V}$ is due to apo C-11 deficiency whereas type $I$ is a result of defective, or absent, apo C-11 or LPL. There are no specific ocular features with either type although corneal arcus may develop in type V. Reports of lipid keratopathy associated with type $\mathbf{I}^{42}$ did not contain sufficient information to discern whether the association was coincidental. 


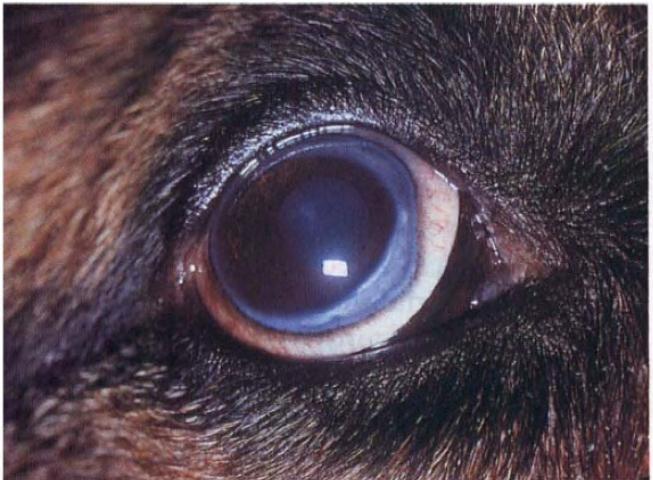

Fig. 9. German Shepherd Dog (male). Corneal arcus (arcus lipoides corneae) associated with primary acquired hypothyroidism. Marked hypercholesterolemia and hypertriglyceridemia. The right eye is shown.

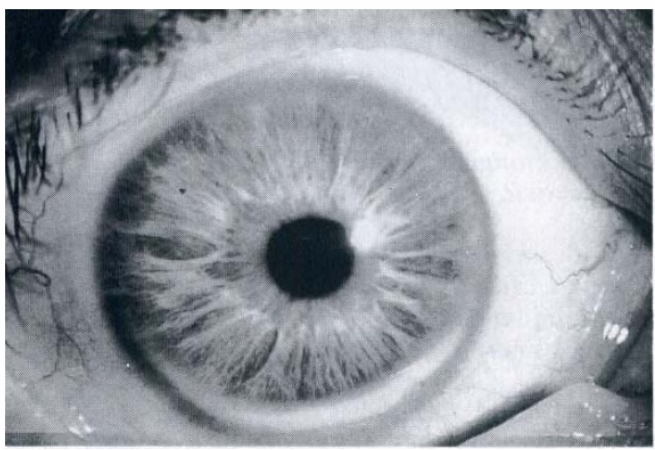

Fig. 11. Human (female). Right eye showing typical corneal arcus. Normolipoproteinemia. (With acknowledgement to Professor C. I. Phillips.)

Crystalline Stromal Dystrophy (Schnyder's Crystalline Corneal Dystrophy)

This inherited disorder has been reported to occur in conjunction with hyperlipoproteinemia in humans ${ }^{43}$ and $\operatorname{dogs} \mathrm{s}^{44}$ and in both species it is possible that crystalline stromal dystrophy is due to a genetically-determined local metabolic defect in the cornea and that the morphological features may be modified by coexisting plasma lipoprotein abnormalities. ${ }^{45}$

\section{Hypolipoproteinemia}

Panstromal lipid deposition has been described in a number of familial HDL deficiency syndromes and in LCAT deficiency;

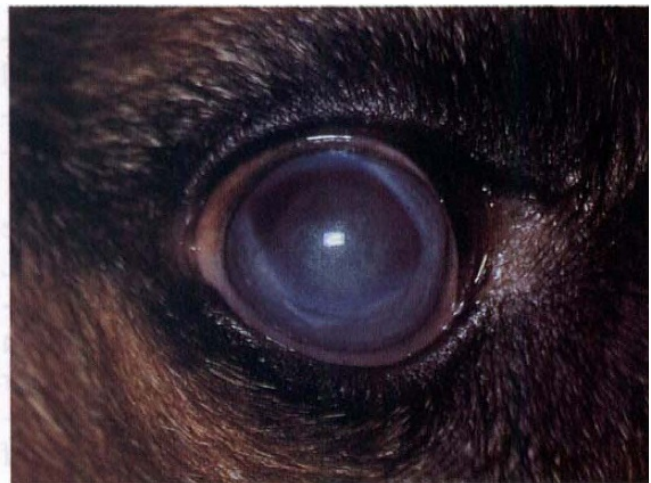

Fig. 10. German Shepherd Dog (male). The left eye of the dog shown in Figure 9. The left cornea is more opaque and has been affected for longer. Fine blood vessels are present in the densest parts of the opacity.

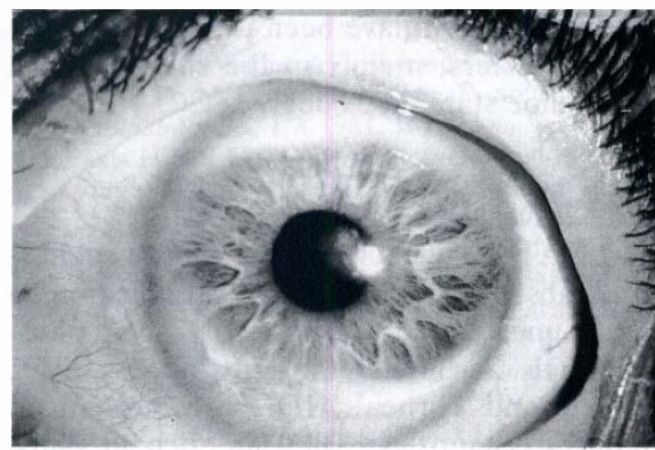

Fig. 12. Human (female). The left eye of the patient shown in Figure 11. The reason for this dense arcus was not clear. Fine blood vessels are apparent in the ventral opacity. (With acknowledgement to Professor C. I. Phillips.)

both classical LCAT deficiency and alpha LCAT deficiency (Fish Eye Disease).

\section{HDL Deficiency Syndromes}

Apo A-1 deficiency is common to all the HDL deficiency syndromes in which corneal opacification has been reported. ${ }^{46}$ The corneal opacity takes the form of a fine granular stromal haze which may be missed unless the cornea is examined with a slit lamp biomicroscope. This panstromal lipid deposit has been described in familial apo A-1 and apo C-111 deficiency, Tangier disease and HDL deficiency with planar xanthomas. In these disorders there is probably defective clearance of lipid from the cornea. ${ }^{47}$ 
In Tangier disease opacities are more concentrated in the periphery and the peripheral density, circumferential with and approximately $0.5 \mathrm{~mm}$ on the corneal side of the limbus, is most apparent at 3 and 9 o'clock. ${ }^{24}$

Patients with this condition usually have reduced levels of total cholesterol and LDL with mild elevation of triglyceride. The morphology of the ultracentrifugal HDL fraction from the plasma of homozygous Tangier patients examined with the electron microscope indicates two distinct populations of particles; one of 15-21 nm diameter and the other of less than $5 \mathrm{~nm}$ diameter. ${ }^{48}$ So the trace amounts of HDL in Tangier plasma differ qualitatively and quantitatively from normal HDL. ${ }^{49}$ The intracellular lipid droplets which accumulate in macrophages in sites such as liver and spleen have been identified as cholesterol esters, mainly in the smectic liquid crystalline state, at 37 degrees $C .^{51}$

\section{LCAT Deficiency}

In LCAT Deficiency Disease there is almost total absence of cholesterol esterification so that unesterified cholesterol and phospholipids accumulate in the kidney, liver, spleen and cornea. HDL are present in reduced quantities. They are rich in phospholipid (lecithin) and unesterified cholesterol and they mainly resemble 'nascent' HDL, mature HDL particles are absent. There may be moderate increases in plasma total cholesterol and triglyceride and VLDL levels are often high.

The corneal appearance is of numerous minute grey, microscopically visible dots which produce corneal haziness and a rather diffuse and soft edged arcus encircling the cornea $^{51}$ (Fig. 13). Anterior and posterior crocodile shagreen has also been reported. ${ }^{52}$ Examination of an affected corne $\mathrm{a}^{53}$ indicated multilaminated accumulation of excess lipid, mainly as phospholipid and cholesterol with a reduced ester content. Cholesterol linoleate was the predominant residue in the cholesterol ester fatty acid fraction, with a C18: $1 / 18: 2$ ratio of $1: 6.5$. This ratio differs from that in normal cornea, and also from that in plasma and other tissue deposits in LCAT deficiency. The corneal findings are consistent with alteration in the character of the accumulating lipid by active local metabolism.

\section{Fish Eye Disease}

In this condition there is a mosaic pattern of diffuse dot like opacities throughout the cornea, but accentuated towards the limbus (Fig. 14). Material from two affected corneas indicated cholesterol and phospholipid enrichment in the stroma and Bowman's membrane. Numerous vacuoles were present between the collagen fibrils, those of Bowman's membrane being smaller and more numerous than those of the stroma. The fibroblasts were not apparently involved..$^{54}$

Plasma lipoprotein abnormalities include hypertriglyceridemia, raised VLDL and

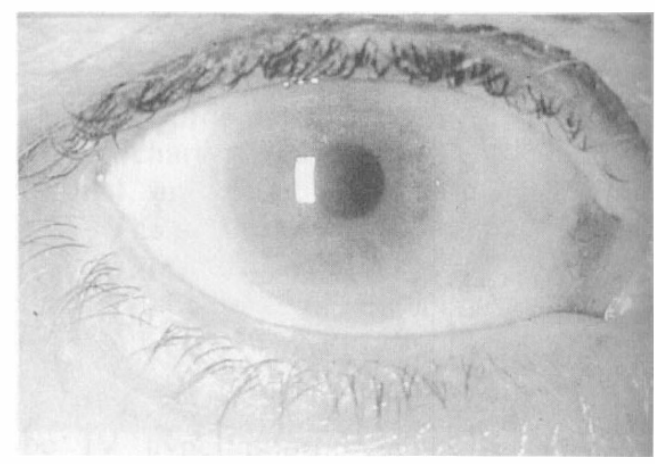

Fig. 13. Human (female). LCAT deficiency, bilateral involvement. (With acknowledgement to Professor A. F. Winder.)
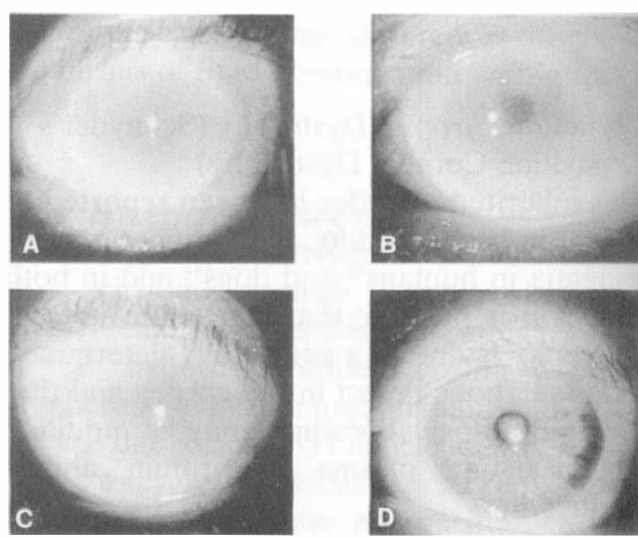

Fig. 14. Human (female). Fish Eye Disease (bilateral involvement). $A$ and $B$ are the eyes of two sisters, $C$ is the eye of an affected unrelated female and $D$ is a normal eye for comparison. (With acknowledgement to Professor L. A. Carlson.) 
reduced concentrations of HDL. ${ }^{55}$ Carlson and Holmquist ${ }^{56}$ demonstrated that the changes are due to a deficiency of plasma alpha-LCAT, (which has HDL as its preferred substrate) in the presenc of normal betaLCAT (which esterifies the cholesterol of LDL and VLDL).

I am grateful to Dr. C. H. Bolton, Mr. A. J. Bron, Professors L. A. Carlson, A. Garner, C. I. Phillips and A. F. Winder for allowing me to use some of their material. I am particularly indebted to Professor A. F. Winder for his help and guidance. My thanks to Mrs. M. Hughes for typing the manuscript and to Mr. J. Connibear and Mr. M. Parsons for some of the photography.

\section{References}

1 Grundy SM: Pathogenesis of hyperlipoproteinemia. J Lipid Res 1984, 25: 1611-18.

${ }^{2}$ Bolton $\mathrm{CH}$ : Lipid disorders. In Holton JB ed. The inherited metabolic diseases, London. Churchill Livingstone 1987: 358-83.

${ }^{3}$ Brown MS and Goldstein JL: Receptor mediated control of cholesterol metabolism. Science 1976, 191: $150-4$.

${ }^{4}$ Courtice FC and Garlick DG: The permeability of the capillary wall to the different plasma lipoproteins of the hypercholesterolemic rabbit in relation to their size. Quart J exp Physiol 1962, 47: 221-7.

${ }^{5}$ Bell FP, Adamson IL, Schwartz CJ: Aortic endothelial permeability to albumin: focal and regional patterns of uptake and transmural distribution of $\mathrm{I}_{131}$ albumin in the young pig. Exp Mol Pathol 1974, 20: 57-68.

${ }^{6}$ Friedman $M$ and Byers SO: Some local factors affecting iridic lipid infiltration in hypercholesterolemic rabbits. Am J Physiol 1959, 197: 842-9.

${ }^{7}$ Friedman $\mathrm{M}$ and Byers SO: Excess lipid leakage: a property of very young vascular endothelium. $\mathrm{Br}$ $J$ exp Path 1962, 43: 363-72.

8 Walton KW: The role of altered vascular permeability in the induction of experimental xanthomata. Nutr Metab 1973, 15: 59-67.

${ }^{9}$ Rippe B, Kamiya A, Folkow B: Transcapillary passage of albumin, effects of tissue cooling and of increases in filtration and plasma colloid osmotic pressure. Acta Physiol Scand 1979, 105: 171-87.

10 Zemplenyi T: Enzyme Biochemistry of the arterial wall. London. Lloyd-Luke, 1968.

11 Cogan DG and Kuwabara T: Lipid keratopathy and atheroma. Circulation 1958, 18: 519-25.

12 Bron AJ and Easty DL: Fluorescein angiography of the globe and anterior segment. Trans ophthalmol Soc UK 1970, 90: 339-67.

${ }^{13}$ Crispin SM: Lipid Keratopathy in the dog. PhD Thesis University of Edinburgh 1984.

${ }^{14}$ Cogan DG and Kuwabara T: Ocular changes in experimental hypercholesterolemia. Arch Ophthalmol 1959, 61: 219-25.

15 Meesman A: Anatomischer befund eines auges mit massenhafter ablagerung von cholesterinkristallen im vorderen kammer und sekundarer atheromatose der hornhaut. Arch $f$ Augenheilk 1924, 94: 56-72.

16 Zeeman WPC and Groen J: Lipidosis corneae. Geneeskundije bladen uit klinick en laboratorium voor de praktijk 1947, 41: 375-411.

${ }^{17}$ Rodger FC: A study of the ultrastructure and cytochemistry of lipid accumulation and clearance in cholesterol-fed rabbit cornea. Exp Eye Res 1971, 14: 88-93.

${ }^{18}$ Landis EM and Pappenheimer JR: Circulation. In Hamilton WF, Dow P eds. Handbook of Physiology, Washington DC: American Physiological Society 1963: Volume 11, Section 2: 961-1034.

${ }^{19}$ Fielder AR, Winder AF, Cooke DE Bowcock SA: Arcus senilis and corneal temperature in man. In Trevor-Roper P ed. Proc Eur Congr Ophthalmol, London: Royal Society of Medicine, 1981: 101520.

${ }^{20}$ Fielder AR, Winder AF, Sheraidah GAK, Cooke ED: Problems with corneal arcus. Trans ophthalmol Soc UK 1981, 101: 22-6.

${ }^{21}$ Forsius $\mathrm{H}$ and Eriksson A: Pterygium and its relation to arcus senilis, pinguecula and other similar conditions. Acta Ophthalmol 1962, 40, 402-10.

22 Macaraeg PVJ Jr, Lasagna L, Snyder B: Arcus not so senilis. Ann Intern Med 1968, 68: 345-54.

${ }^{23}$ Winder AF: Relationship between corneal arcus and hyperlipidemia is clarified by studies in familial hypercholesterolemia. Br J Ophthalmol 1981, 67: 789-94.

${ }^{24}$ Spaeth GL: Ocular manifestations of the lipidoses In Tasman W ed. Retinal diseases in children, New York: Harper and Row 1971: 127-206.

25 Small DM and Shipley GG: Physical-chemical basis of lipid deposition in atherosclerosis. Science 1974, 185: 222-9.

${ }^{26}$ Smith EB: Molecular interactions in human atherosclerotic plaques. Am J Pathol 1977, 86: 66574.

${ }^{27}$ Small DM: Progression and regression of atherosclerotic lesions. Arteriosclerosis 1988, 8: 103 29.

${ }^{28}$ Camejo G: The interaction of lipids and lipoproteins with the intercellular matrix of arterial tissue; its possible role in atherogeneis. Adv Lipid Res 1982, 19: $1-53$.

${ }^{29}$ Borcherding MS, Blacik LJ, Sittig RA, Bizzell JW, Breen M, Weinstein HG: Proteoglycans and collagen fibre organisation in human corneoslceral tissue. Exp Eye Res 1975, 21: 59-70.

${ }^{30}$ Sheraidah GAK, Winder AF, Fielder AR: Lipidprotein constituents of human corneal arcus. Atherosclerosis 1981, 40: 91-8.

31 Camejo G, Olofsson S-O, Lopez F, Carlson P, Bondjers G: Identification of apo-B100 segments mediating the action of low density lipoproteins with arterial proteoglycans. Arteriosclerosis 1988 , 8: $368-77$ 
${ }^{32}$ Tschetter RT: Lipid analysis of the human cornea with and without arcus senilis. Arch Ophthalmol 1976, 76: 403-5.

${ }^{33}$ Deckelbaum RJ, Shipley GG, Small DM: Structure and interactions of lipids in human plasma low density lipoproteins. J Biol Chem 1977, 252: 744 54.

34 Yamashita S, Matsuzawa Y, Kubo M, Tarui S: Coronary heart disease and corneal opacification in hyperalphalipoproteinemia. Arteriosclerosis 1987, 7: 504a.

${ }^{35}$ Beaumont JL, Carlson LA, Cooper GR, Fejfar Z, Fredrickson DS, Strasser T: Classification of hyperlipidemias and hyperlipoproteinemias. Bull WHO 1970, 43: 891-915.

${ }^{36}$ Fredrickson DS, Goldstein JL, Brown MS: The familial hyperlipoproteinemais. In Stansbury JB, Wyngaarden JB, Fredrickson DS eds. The metabolic basis of inherited disease 4th ed. New York. McGraw-Hill 1978: 604-55.

${ }^{37}$ Winder AF: Disorders of lipid and lipoprotein metabolism. In Garner A, Klintworth GK eds. Pathobiology of ocular disease Part B, Switzerland: Marcel Dekker 1982: 1047-75.

38 Thompson GR, Soutar AK, Spengel FA, Jadhav A, Gavigan S, Myant NB: Defects of the receptormediated low density lipoprotein catabolism in homozygous familial hypercholesterolemia and hypothyroidism in vivo. Proc Nat Ac Sci 1981, 78: 2591-2595.

${ }^{39}$ Crispin SM and Barnett KC: Arcus lipoides corneae secondary to hypothroidism in the Alsatian. $J$ Small Anim Pract 1978, 19: 127-42.

${ }^{40}$ Cogan DG and Kuwabara T: Arcus senilis, its pathology and histochemistry. Arch Ophthalmol 1959, 61: $553-60$.

${ }^{41}$ Winder AF: Ophthalmological complications of the hypertriglyceridemia. Trans Ophthalmol Soc UK 1980, 100: 119-22.

42 Vinger PF and Sachs BA: Ocular manifestations of hyperlipoproteinemia. Am J Ophthalmol 1970, 70: $563-73$.

${ }^{43}$ Williams HP, Bron AJ, Tripathi RC, Garner A: Hereditary crystalline corneal dystrophy with an associated blood lipid disorder. Trans Ophthalmol Soc UK 1971, 91: 531-42.

${ }^{44}$ Crispin SM: Crystalline stromal dystrophy in the dog. Cornea 1988, 7: 149-61.

${ }^{45}$ Bron AJ: Corneal changes in the dyslipoproteinemias. Cornea 1988 (in press).

${ }^{46}$ Schaefer EJ: Clinical, biochemical, and genetic features in familial disorders of high density lipoprotein deficiency. Arteriosclerosis 1984, 4: 303-22.

47 Winder AF and Borysiewicz LK: Corneal opacification and familial disorders affecting plasma high density lipoprotein. Birth Defects Original Article Series 1982, 18: 433-40.

${ }^{48}$ Forte T and Nichols AV: Application of electron microscopy to the study of plasma lipoprotein structure. Adv Lipid Res 1972, 10: 1-41.

${ }^{49}$ Herbert PN, Gotto AM, Fredrickson DS: Familial lipoprotein deficiency. In Stansbury JB, Wyngaarden JB, Fredrickson DS eds. The metabolic basis of inherited disease 4th ed. New York. McGraw-Hill 1978: 544-88.

${ }^{50} \mathrm{Katz}$ SS, Small DM, Brook JG, Lees RS: The storage lipids in Tangier disease. J Clin Invest 1977, 59: 1045-54.

${ }^{51}$ Gjone E and Bergaust B: Corneal opacity in familial plasma cholesterol ester deficiency. Acta Ophthalmol 1969, 47: 222-7.

52 Vrabec MP, Shapiro MB, Koller E, Wiebe DA, Herricks MS, Albers JJ: Ophthalmic observations in lecithin cholesterol acyltransferase deficiency. Arch Ophthalmol 1988, 106: 225-9.

${ }^{53}$ Winder AF, Garner A, Sheraidah GA, Barry P: Familial lecithin: cholesterol acyltransferase deficiency. Biochemistry of the cornea. J Lipid res 1985, 26: 283-7.

${ }^{54}$ Philipson BT: Fish eye disease. Birth Defects Original Article Series 1982, 18: 441-8.

${ }^{55}$ Carlson LA and Philipson BT: Fish Eye Disease, a new familial condition with massive corneal opacities and dyslipoiproteinemia. Lancet 1979 , ii: $921-3$.

${ }^{56}$ Carlson LA and Holmquist L: Evidence for deficiency of high density lipoiprotein lecithin: cholesterol acyltransferase activity (alpha-LCAT) in Fish Eye Disease. Acta Med Scand 1985, 218: 180-96. 